\title{
Equilibrium Isotherm Studies of Adsorption of Pigments Extracted from Kuduk-kuduk (Melastoma malabathricum L.) Pulp onto $\mathrm{TiO}_{2}$ Nanoparticles
}

\author{
N. T. R. N. Kumara, ${ }^{1}$ Nurulhayah Hamdan, ${ }^{1}$ Mohammad Iskandar Petra, ${ }^{2}$ \\ Kushan U. Tennakoon, ${ }^{3}$ and Piyasiri Ekanayake ${ }^{1}$ \\ ${ }^{1}$ Applied Physics Program, Faculty of Science, Universiti Brunei Darussalam, Jalan Tungku Link, Gadong BE1410, Brunei Darussalam \\ ${ }^{2}$ Faculty of Integrated Technology, Universiti Brunei Darussalam, Jalan Tungku Link, Gadong BE1410, Brunei Darussalam \\ ${ }^{3}$ Biology Program, Faculty of Science, Universiti Brunei Darussalam, Jalan Tungku Link, Gadong BE1410, Brunei Darussalam
}

Correspondence should be addressed to Piyasiri Ekanayake; piyasiri.ekanayake@ubd.edu.bn

Received 14 May 2013; Revised 25 September 2013; Accepted 24 October 2013; Published 12 January 2014

Academic Editor: Mohammad El-Shahawi

Copyright (c) 2014 N. T. R. N. Kumara et al. This is an open access article distributed under the Creative Commons Attribution License, which permits unrestricted use, distribution, and reproduction in any medium, provided the original work is properly cited.

\begin{abstract}
The adsorption of natural pigments onto $\mathrm{TiO}_{2}$ nanoparticles was investigated. The pigments were extracted from the dark purple colored pulp of the berry-like capsule of Kuduk-kuduk (Melastoma malabathricum L.). The Langmuir, Freundlich, RedlichPeterson, and Sips isotherm models were used to analyze the equilibrium experimental data. Data correlated well with the Sips isotherm model, where the heterogeneity factor $(n=0.24)$ indicated heterogeneous adsorption characteristics, with a maximum adsorption capacity of $0.0130 \mathrm{mg} / \mathrm{g}$. The heterogeneous adsorption character was further supported by results obtained from zetapotential measurements. When a dye-sensitized solar cell (DSSC) was sensitized with the extracted pigment, the photo-energy conversion efficiency was measured to be $0.83 \%$, thus proving the suitability of Kuduk-kuduk fruit pulp as a sensitizer in DSSCs.
\end{abstract}

\section{Introduction}

Commercially, the quality of a product depends on the product value and acceptability. However, consumers are also attracted to the physical appearances of the product, especially to its colors. In food, beverages, and textile industries, the pigments are employed as coloring agents and for dyeing purposes. Natural colorants extracted from plants have been used for centuries before the first synthetic colorant was introduced. Low cost and ease of application have driven the drift from natural colorants to synthetic. However, due to environmental and health concerns associated with the applications of synthetic colorants the interest of using natural and organic sources as colorants has increased lately.

Anthocyanins are natural, water-soluble, and nontoxic pigments which are responsible for the red, orange, pink, blue, or purple color of plants. The resultant color variation depends on the relative $\mathrm{pH}$ of the respective plant [1]. The anthocyanin pigments are expressed as red or pink under acidic media, purple in neutral media, and blue, green, or yellow in alkaline media. It turns colorless under extreme alkaline conditions [2]. Thus, anthocyanins also can be used as a $\mathrm{pH}$ indicator. Anthocyanins have been employed as additives or colorants in the food industry with limited usage due to its instability with varying $\mathrm{pH}$ levels [1]. In the alternative energy sector, natural dye extracts containing anthocyanins are integrated as sensitizers in dye-sensitized solar cells (DSSCs) because of their ability to absorb light $[3,4]$ and low cost associated with extraction procedures.

Many researches had been conducted on analyzing the potential anthocyanins sensitizers extracted from natural resources $[5,6]$, and currently an efficiency of natural sensitized DSSC of about 2\% [4, 7] has been achieved. The performance and the efficiency of the DSSCs can be enhanced by increasing the adsorption capacity of the anthocyanins sensitizer onto the $\mathrm{TiO}_{2}$ nanoparticles surface and selecting pigments with broader absorption capacity. Adsorption is defined as the binding of molecules or particles (adsorbates) 
onto a surface (adsorbent). In this study adsorbate and adsorbent are anthocyanin pigments and $\mathrm{TiO}_{2}$ nanoparticles, respectively.

Kuduk-kuduk (KK) also known as Malabar Melastome (Melastoma malabathricum L.), is a shrub belonging to the family Melastomataceae. This is naturally grown in the disturbed tropical and subtropical habitats under full sunlight [8]. The flower is purple (sometimes pink), while the fruit a berry-like capsule filled with purple color pulp with numerous seeds. The purple-pink color of the flower petals as well as the fruit pulp is due to anthocyanin pigments [9]. These features make it a valuable ornamental plant and a potential source for natural colorants.

Currently, many researchers are focusing to achieve highly efficient DSSCs with natural sensitizers [4]. In order to achieve high efficiency in natural sensitized DSSCs, in addition to absorption capacities, the adsorption properties of the pigments onto $\mathrm{TiO}_{2}$ nanoparticles have to be investigated and improved [10]. The aim of this work is to investigate the adsorption properties of anthocyanin pigments extracted from KKP (KK fruit pulp) onto the surface of $\mathrm{TiO}_{2}$ nanoparticles using the Langmuir, Freundlich, Redlich-Peterson, and Sips isotherm models and to evaluate its potential as a natural sensitizer in DSSCs.

\section{Experimental}

2.1. Preparation and Characterization of Adsorbate. The natural anthocyanin-containing dye, used in this study, was extracted from KKP. $20 \mathrm{~g}$ (fresh weight) of the clean pulp was ground with a small amount of $70 \%$ ethanol (diluted from Scharlau 99.9\% with distilled water). The crushed sample was mixed with $150 \mathrm{~mL}$ of $70 \%$ ethanol solution using a vortex mixture and kept at room temperature $\left(25^{\circ} \mathrm{C}\right)$ overnight covered with an aluminum foil to ensure no exposure to outside light. The residues of the filtrate were removed by filtering through a filter paper (Whatman, Grade 1). The absorption spectra of the KKP extract were investigated in the range 400 to $700 \mathrm{~nm}$ using UV-vis spectrophotometer (1601 PC Shimadzu). According to absorption data in [11] the predominant anthocyanin present in KKP extract is cyanidin-3-glucoside. The total monomeric concentration of anthocyanin pigments in the dye extract was determined by using the $\mathrm{pH}$-differential method [11] which is based on the difference in the pigments absorbance measurement at wavelengths of $520 \mathrm{~nm}$ and $700 \mathrm{~nm}$ :

$$
\text { Anthocyanin pigment content }(\mathrm{mg} / \mathrm{L})
$$

$$
=\frac{A \times \mathrm{MW} \times \mathrm{DF} \times 10^{3}}{\varepsilon \times l},
$$

where $A=\left(A_{520 \mathrm{~nm}}-A_{700 \mathrm{~nm}}\right) \mathrm{pH} 1.0-\left(A_{520 \mathrm{~nm}}-A_{700 \mathrm{~nm}}\right)$ $\mathrm{pH} 4.5$, MW (molecular weight) $=449.2 \mathrm{~g} / \mathrm{mol}$ for cyanidin3-glucoside (cyd-3-glu), DF = dilution factor, $\varepsilon$ (molar extinction coefficient) $=26900 \mathrm{~L} \mathrm{~mol}^{-1} \mathrm{~cm}^{-1}, 10^{3}$ is the factor for converting $\mathrm{g}$ to $\mathrm{mg}$, and $l$ is the path length in $\mathrm{cm}$.

2.2. Adsorption Studies. Adsorption isotherms of this study were carried out at different concentrations of KKP extract; a dilution series of six samples was prepared by mixing 0.25 to $0.5 \mathrm{~mL}$ of $\mathrm{KKP}$ extracts with absolute ethanol up to a volume of $10 \mathrm{~mL}$. $20 \mathrm{mg}$ of commercially available Degussa P25 (mean particle diameter of $30 \mathrm{~nm}, 70 \%$ anatase, $30 \%$ rutile, and specific surface area of $50 \mathrm{~g} \mathrm{~m}^{-2}$ ) $\mathrm{TiO}_{2}$ powder was mixed into each sample and kept overnight at room temperature $\left(25^{\circ} \mathrm{C}\right)$ without exposing to external light to ensure a good adsorption. The liquid phase of each mixture was separated after centrifuging for $10 \mathrm{~min}$ at $3000 \mathrm{rpm}$ in a centrifuge (SiGma 3-18 k). The absorbance of KKP extract pigments in the solution, before and after adsorption, was measured at $520 \mathrm{~nm}$. The adsorbed amount of KKP extract pigments at equilibrium, $q_{e}(\mathrm{mg} / \mathrm{g})$, was calculated using the mass balance equation [12]:

$$
q_{e}=\frac{v\left(C_{i}-C_{e}\right)}{m},
$$

where $C_{i}$ and $C_{e}(\mathrm{mg} / \mathrm{L})$ are the initial and equilibrium concentrations of KKP extract pigments solution, respectively, $V$ is the volume of the solution used (L), and $m$ is the mass of the dry adsorbent $\left(\mathrm{TiO}_{2}\right.$ nanoparticles) (g). The Langmuir, Freundlich, Redlich-Peterson, and Sips isotherms were used to analyze the equilibrium data.

2.3. Zeta-Potential and I-V Measurements. The zeta-potential of the KKP extract at original $\mathrm{pH}$ was measured using Zetasizer (Nano MAN 0317) at a temperature of $25.0^{\circ} \mathrm{C}$ in ethanol solution. In order to prepare the $\mathrm{TiO}_{2}$ paste, a mixture of $0.20 \mathrm{~g}$ of $\mathrm{TiO}_{2}$ (Degussa P-25), 12 drops (0.15 g) of glacial acetic acid, one drop ( $0.02 \mathrm{~g})$ of triton $\mathrm{X}-100$, and $2 \mathrm{~mL}$ of ethanol were ground in a ball-mill machine (Paul O. Abbe Roller Mill, Model 202421) for $20 \mathrm{~h}$. Subsequently the $\mathrm{TiO}_{2}$ paste was coated on precleaned fluorine-doped conducting tin oxide (FTO) glasses (Nippon sheet glass $10-12 \Omega \mathrm{sq}^{-1}$ ) by Doctor Blade method. The coated film was sintered for $45 \mathrm{~min}$ at $450^{\circ} \mathrm{C}$. The thickness of sintered $\mathrm{TiO}_{2}$ electrode was $\sim 9 \mu \mathrm{m}$ (Dektak Profilometer; Veeco, Dektak 3). This electrode was dipped in the KKP extract overnight at room temperature $\left(25^{\circ} \mathrm{C}\right)$ and air-dried at the same temperature [13]. The active solar cell area was $0.25 \mathrm{~cm}^{2}$. The cell was assembled using a Test Cell Assembly Machine (Dyesol) with the Surlyn $(50 \mu \mathrm{m}$, Dyesol) as the spacer. A mixture of tetrabutylammonium iodide (TBAI; $0.5 \mathrm{M}) / \mathrm{I}_{2}(0.05 \mathrm{M})$, acetonitrile, and ethylene carbonate $(6: 4, v / v)$ was used as redox electrolyte [14]. The assembled solar cell was kept under 1 sun (Dyesol Solar Simulator LP-156B) for about $4 \mathrm{~h}$ for light soaking. Finally, $I-V$ characteristic of the DSSC was measured.

\section{Results and Discussion}

3.1. The Optical Properties. The UV-vis absorption spectra of KKP extract confirmed the presence of anthocyanin pigments. It produced a prominent peak at the wavelength of $520 \mathrm{~nm}$ when a drop of $\mathrm{HCl}$ was added into the original KKP extract [11]. 
TABLE 1: The parameters required for kinetic adsorption isotherm study.

\begin{tabular}{lccc}
\hline Vol. of dye extract $(\mathrm{mL})$ & $C_{i}(\mathrm{mg} / \mathrm{L})$ & $C_{e}(\mathrm{mg} / \mathrm{L})$ & $q_{e}(\mathrm{mg} / \mathrm{g})$ \\
\hline 0.25 & 0.02145 & 0.00765 & 0.00686 \\
0.30 & 0.02574 & 0.00914 & 0.00826 \\
0.35 & 0.03003 & 0.00963 & 0.00995 \\
0.40 & 0.03433 & 0.01112 & 0.01178 \\
0.45 & 0.03860 & 0.01459 & 0.01166 \\
0.50 & 0.04290 & 0.01756 & 0.01280 \\
\hline
\end{tabular}

3.2. Kinetic Adsorption Studies. The parameters required for kinetic adsorption isotherm study are summarized in Table 1. The occurrence of the adsorption process was signified from the differences shown among the values of $C_{i}$ and $C_{e}$, where a decrease in the concentration of anthocyanin pigments was observed. The amount of anthocyanin pigments adsorbed per unit mass of $\mathrm{TiO}_{2}$ is shown in Table 1 .

Adsorption isotherms models describe the distribution of the adsorbate species between liquid and adsorbent through linearly plotted graphs based on a set of assumptions y related to the heterogeneity or homogeneity of adsorbents, the type of coverage, and the possibility of interaction between the adsorbates [15].

3.2.1. Langmuir Isotherm. The Langmuir adsorption isotherm model explains the variation of adsorption of molecules (adsorbates) with pressure. The isotherm is based on the assumption that maximum adsorption occurs when a saturated monolayer of adsorbate molecules is present on the adsorbent surface, the energy of adsorption is constant, and there is no migration or interaction between the adsorbate molecules in the surface plane $[16,17]$. The linear expression of the Langmuir isotherm model is defined by

$$
\frac{1}{q_{e}}=\frac{1}{q_{m} K_{L}} \cdot \frac{1}{C_{e}}+\frac{1}{q_{m}} .
$$

By plotting the linear graph of $1 / q_{e}$ against $1 / C_{e}$, the values of $K_{L}$ and $q_{m}$ can be determined from the intercept and slope of the plot (Figure 1), where the parameter $q_{m}(\mathrm{mg} / \mathrm{g})$ is the maximum adsorption capacity of dye per unit mass of sorbent to form a complete monolayer on the surface bound at high $C_{e}$ and $K_{L}(\mathrm{~L} / \mathrm{mg})$ is the Langmuir energy constant which is related to the heat of adsorption. Table 2 presents the values of Langmuir constants $\left(q_{m}=0.0468 \mathrm{mg} / \mathrm{g}, K_{L}=28.489 \mathrm{~L} / \mathrm{mg}\right)$. The essential characteristics of the Langmuir isotherm can be expressed in terms of a dimensionless constant separation factor $R_{L}$ that is given by

$$
R_{L}=\frac{1}{\left(1+K_{L} C_{i}\right)},
$$

where $C_{i}(\mathrm{mg} / \mathrm{L})$ is the highest initial concentration of adsorbate and $R_{L}$ values between 0 and 1 imply favorable adsorption. The value of $R_{L}$ in the present investigation was calculated to be 0.45 which indicates favorable adsorption of KKP extract pigments onto $\mathrm{TiO}_{2}$ nanoparticles surface.

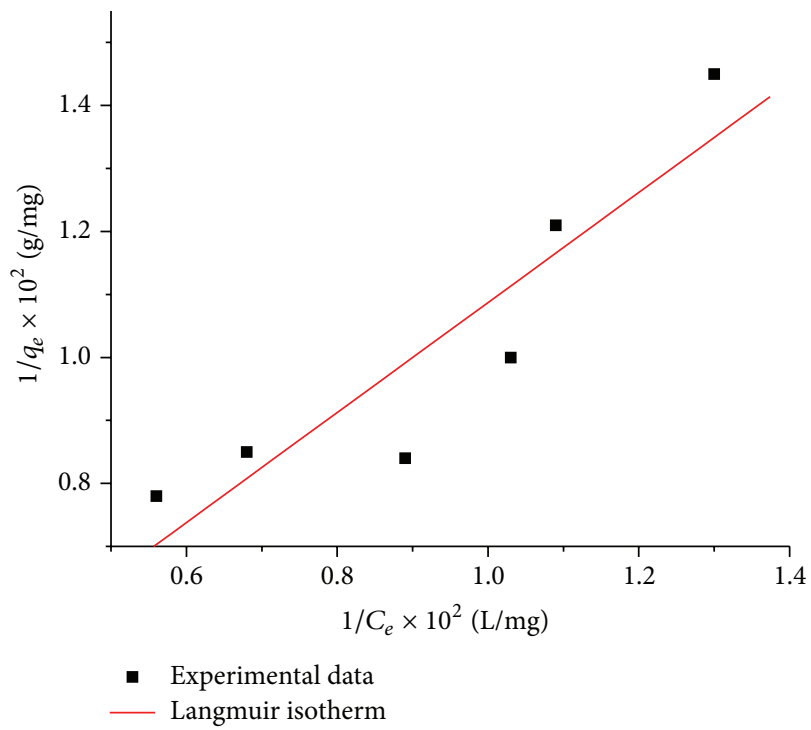

FIGURE 1: Langmuir adsorption isotherm and experimental data of KKP extract.

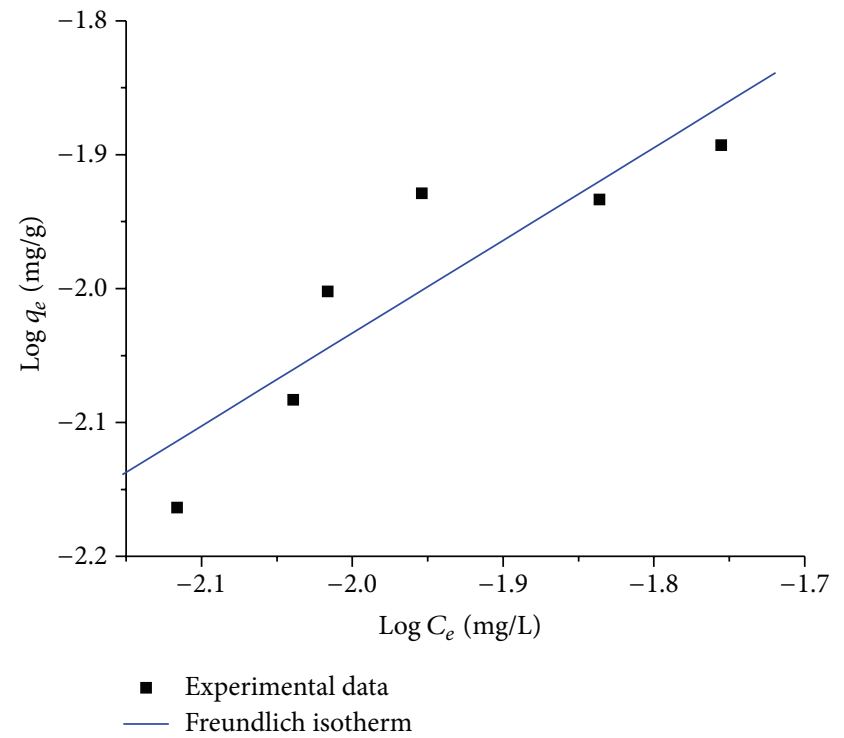

FIgURE 2: Freundlich adsorption isotherm and experimental data of KKP extract.

3.2.2. Freundlich Isotherm. The Freundlich isotherm explains that the extent of adsorption varies directly with pressure. This empirical relationship describes the multilayer adsorption of heterogeneous systems and assumes that different sites have several adsorption energies involved [18]. The linear model of the isotherm can be expressed logarithmically as in

$$
\log q_{e}=\frac{1}{n} \log C_{e}+\log K_{F} .
$$

The values of parameters $K_{F}$ and $n$ (listed in Table 2) can be determined from the intercept and slope of the plot $\log C_{e}$ against $\log q_{e}$ (Figure 2), where $K_{F}(1 / \mathrm{g})$ is the Freundlich adsorption capacity constant and $1 / n$ is related 
TABLE 2: Parameters and correlation coefficient $\left(R^{2}\right)$ of equilibrium isotherm models for the adsorption of $\mathrm{KKP}$ extract pigments onto TiO 2 nanoparticles.

\begin{tabular}{|c|c|c|c|}
\hline Isotherm & Equation & Parameters & $R^{2}$ \\
\hline Langmuir & $\frac{1}{q_{e}}=\frac{1}{q_{m} K_{L}} \cdot \frac{1}{C_{e}}+\frac{1}{q_{m}}$ & $\begin{aligned} K_{L} & =28.489 \mathrm{~L} / \mathrm{mg} \\
q_{m} & =0.047 \mathrm{mg} / \mathrm{g}\end{aligned}$ & 0.915 \\
\hline Freundlich & $\log q_{e}=\frac{1}{n} \log C_{e}+\log K_{F}$ & $\begin{array}{c}K_{F}=0.225(1 / g) \\
\frac{1}{n}=0.69\end{array}$ & 0.893 \\
\hline Redlich-Peterson & $\ln \left(K_{R} \frac{C_{e}}{q_{e}}-1\right)=b_{R} \ln C_{e}+\ln a_{R}$ & $\begin{array}{c}K_{R}=10 \mathrm{mg} / \mathrm{g} \\
a_{R}=45.814 \mathrm{mg} / \mathrm{L} \\
b_{R}=0.335\end{array}$ & 0.657 \\
\hline Sips & $\frac{1}{q_{e}}=\frac{1}{Q_{\max } K_{s}}\left(\frac{1}{C_{e}}\right)^{1 / n}+\frac{1}{Q_{\max }}$ & $\begin{array}{c}K_{S}=6.97 \times 10^{8} \mathrm{~L} / \mathrm{mg} \\
Q_{\max }=0.0130 \mathrm{mg} / \mathrm{g} \\
n=0.24\end{array}$ & 0.971 \\
\hline
\end{tabular}

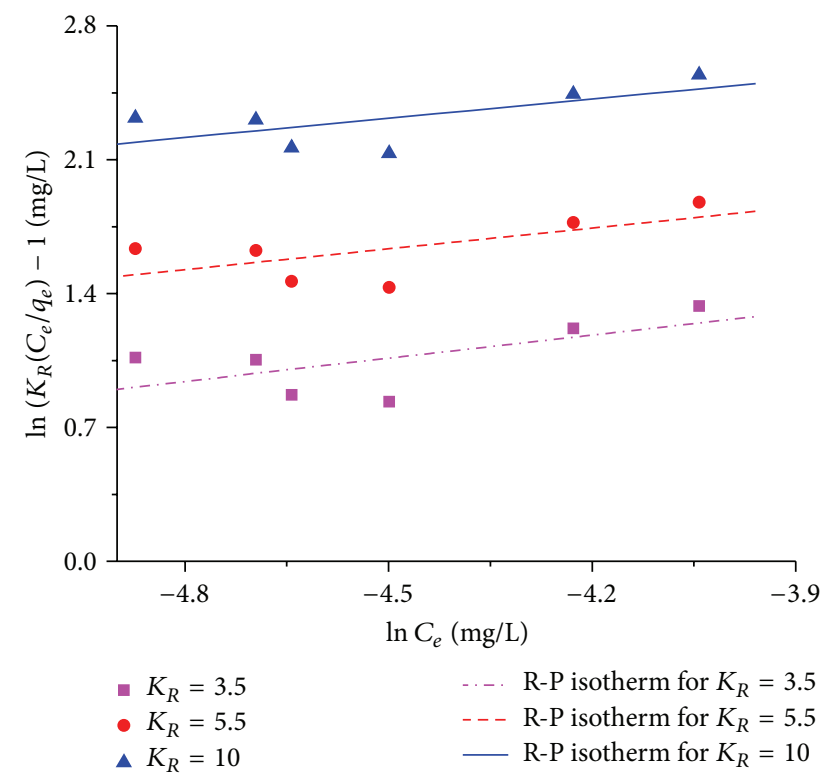

FIGURE 3: Redlich-Peterson adsorption isotherm and experimental data of KKP extract.

to the adsorption intensity constant that varies with the heterogeneity of the adsorbate.

3.2.3. Redlich-Peterson Isotherm. The Redlich-Peterson (R-P) isotherm is a three-parameter empirical adsorption model that incorporates elements from both the Langmuir and Freundlich isotherms [15] and amends the inaccuracies. The adsorption mechanism is unique and does not follow ideal monolayer adsorption characteristics. The linear expression of the R-P isotherm model is defined as [15]

$$
\ln \left(K_{R} \frac{C_{e}}{q_{e}}-1\right)=b_{R} \ln C_{e}+\ln a_{R},
$$

where $K_{R}$ is the Redlich-Peterson adsorption capacity constant determined via trials and errors to obtain the maximum linear regression value of the isotherm graph (Figure 3). The parameter $a_{R}$ is the R-P isotherm constant and $b_{R}$ is the exponent between 0 and 1 . Numerous studies [1924] have shown that the R-P isotherm was more accurate than the Langmuir and Freundlich isotherms as it contains three unknown parameters. The reason for this is that the Langmuir and Freundlich isotherms can be derived from the R-P isotherm. When $b_{R}=1$, the R-P equation becomes the Langmuir isotherm equation and when $b_{R}=0$, it is closer to the Freundlich equation. However, the accuracy of these interpretations strongly depends on the fitting method [2528].

3.2.4. Sips Isotherm. The Sips isotherm is derived from the limiting behavior of the Langmuir and Freundlich isotherms. The model is valid for localized adsorption without adsorbate-adsorbate interactions [15]. When $C_{e}$ approaches a low value, the Sips isotherm effectively reduces to Freundlich, while at high $C_{e}$, it predicts the Langmuir monolayer sorption characteristic. The Sips linear equation model is expressed as [15]

$$
\frac{1}{q_{e}}=\frac{1}{Q_{\max } K_{S}}\left(\frac{1}{C_{e}}\right)^{1 / n}+\frac{1}{Q_{\max }},
$$

where $K_{S}(1 / \mathrm{mg})$ and $Q_{\max }(\mathrm{mg} / \mathrm{g})$ are the Sips equilibrium constant and maximum adsorption capacity values obtained from the slope and the intercept of the plot (Figure 4). The Sips isotherm equation is characterized by the dimensionless heterogeneity factor, $n$, which can also be employed to describe the system's heterogeneity when $n$ is between 0 and 1. When $n=1$, the Sips equation reduces to the Langmuir equation and it implies a homogeneous adsorption process [21].

The parameters and correlation coefficient $\left(R^{2}\right)$ for each of the equilibrium isotherm models of the adsorption process are shown in Table 2 . The Redlich-Peterson model clearly shows poor correlation $\left(R^{2}=0.657\right)$ to the experimental data. Similarly, the Freundlich isotherm model that assumes an exponential increase in the adsorption amount does not fit well with data $\left(R^{2}=0.893\right)$. Both the Langmuir $\left(R^{2}=\right.$ 0.915) and Sips isotherm $\left(R^{2}=0.971\right)$ models show good fit to experimental data. However, heterogeneous adsorption 


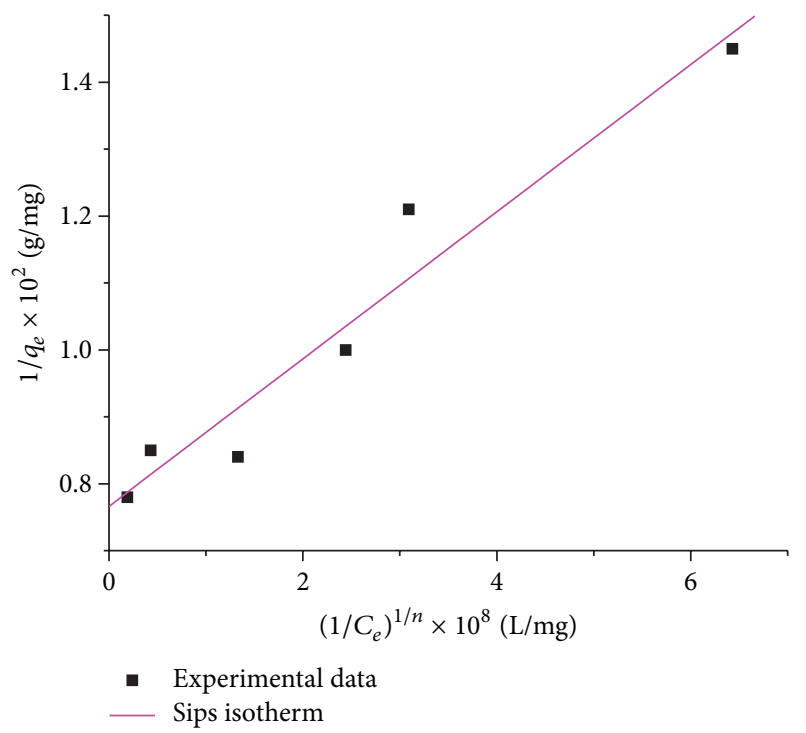

Figure 4: The Sips adsorption isotherm and experimental data of KKP extract.

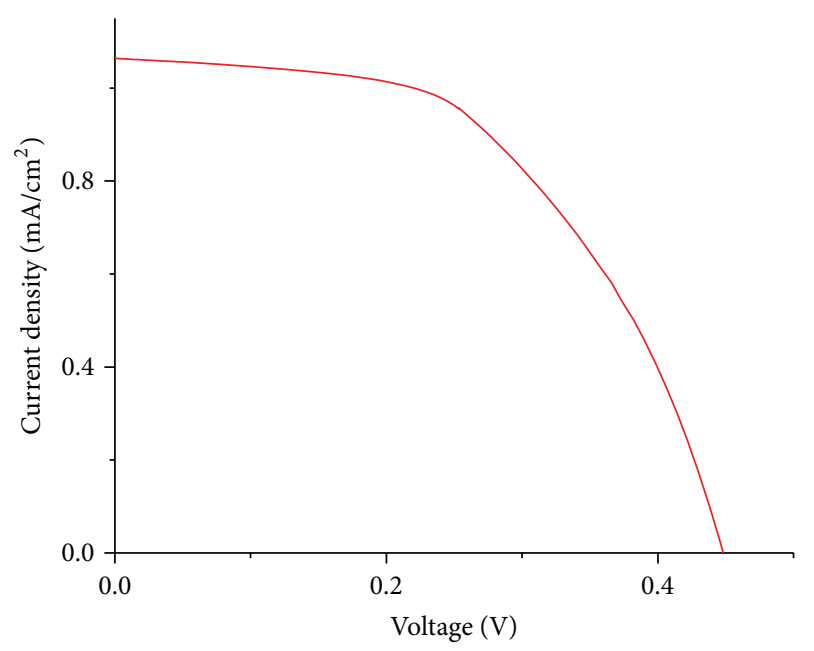

FIGURE 5: $I-V$ characteristics of DSSC sensitized with KKP extract.

process is evidently indicated from the heterogeneity factor value $(n=0.24)$. Thus, the isotherm that best describes the adsorption behavior of KKP extract pigments onto the $\mathrm{TiO}_{2}$ nanoparticles is the Sips isotherm.

3.3. Zeta-Potential and Photovoltaic Performance in DSSC. For KKP extract, zeta-potential of $-9.48 \mathrm{mV}$ was obtained. This indicates the tendency of anthocyanin pigment molecules coagulating at its original $\mathrm{pH}(\sim 5)$, which correlates well with the pigment's adsorption characteristics as explained by the Sips isotherm.

The DSSC performance was examined using the currentvoltage characteristics, as shown in Figure 5. The values obtained for open circuit voltage $\left(V_{\mathrm{OC}}\right)$, short circuit current density $\left(J_{\mathrm{SC}}\right)$, and fill factor $(f f)$ were $0.448 \mathrm{~V}, 3.177 \mathrm{~mA} / \mathrm{cm}^{2}$, and 0.52 , respectively. Although monolayer adsorption condition is favorable for the photoconversion of DSSC anode
[29], the KKP extract that showed multilayer adsorption characteristics has demonstrated its capability of sensitizing DSSCs while giving a photoenergy conversion efficiency of $0.83 \%$.

\section{Conclusions}

The adsorption behavior of KKP extract containing anthocyanin onto $\mathrm{TiO}_{2}$ nanoparticles surface was investigated. Experimental data were modeled using the Langmuir, Freundlich, Redlich-Peterson, and Sips isotherms. Equilibrium adsorption of KKP extract pigments onto $\mathrm{TiO}_{2}$ was well described by the Sips model with a heterogeneous adsorption capacity of $0.0130 \mathrm{mg} / \mathrm{g}$. Zeta-potential data revealed the tendency of pigment molecule coagulation in the solvent. This phenomenon correlated well with its adsorption behavior. From $I-V$ analysis, a photo-energy conversion efficiency of $0.83 \%$ was obtained indicating that the Kuduk-kuduk fruitpulp extraction has the potential to be integrated into the dyesensitized solar cell system as a viable sensitizer.

\section{Conflict of Interests}

The authors declare that there is no conflict of interests regarding the publication of this paper.

\section{Acknowledgments}

The Universiti Brunei Darussalam Research Grant UBD/PNC2/2/RG/1(176) and Brunei Research Council (BRC) Science and Technology Grant (S \& $\mathrm{T}$ 17) are acknowledged for financial support.

\section{References}

[1] J. Li, X. D. Li, Y. Zhang et al., "Identification and thermal stability of purple-fleshed sweet potato anthocyanins in aqueous solutions with various $\mathrm{pH}$ values and fruit juices," Food Chemistry, vol. 136, no. 3-4, pp. 1429-1434, 2013.

[2] A. Andres-Bello, V. B. Palacios, P. Garcia-Segovia, J. Mir-Bel, and J. Martinez-Monzo, "Effect of $\mathrm{pH}$ on color and texture of food products," Food Engineering Reviews, vol. 5, no. 3, pp. 158170,2013

[3] J. S. de Souza, L. O. M. de Andrada, and A. S. Polo, "Nanomaterials for solar energy conversion: dye-sensitized solar cells based on ruthenium (II) Tris-heteroleptic compounds or natural dyes," in Nanoenergy, F. L. de Souza and E. R. Leite, Eds., pp. 49-80, Springer, Berlin, Germany, 2013.

[4] M. R. Narayan, "Review: dye sensitized solar cells based on natural photosensitizers," Renewable and Sustainable Energy Reviews, vol. 16, no. 1, pp. 208-215, 2012.

[5] H. Zhou, L. Wu, Y. Gao, and T. Ma, "Dye-sensitized solar cells using 20 natural dyes as sensitizers," Journal of Photochemistry and Photobiology A, vol. 219, no. 2-3, pp. 188-194, 2011.

[6] M. Shahid, S. Ul-Islam, and F. Mohammad, "Recent advancements in natural dye applications: a review," Journal of Cleaner Production, vol. 53, pp. 310-331, 2013. 
[7] G. Calogero, J.-H. Yum, A. Sinopoli, G. Di Marco, M. Grätzel, and M. K. Nazeeruddin, "Anthocyanins and betalains as lightharvesting pigments for dye-sensitized solar cells," Solar Energy, vol. 86, no. 5, pp. 1563-1575, 2012.

[8] S. M. Joffry, N. J. Yob, M. S. Rofiee et al., "Melastoma malabathricum (L.) smith ethnomedicinal uses, chemical constituents, and pharmacological properties: a review," EvidenceBased Complementary and Alternative Medicine, vol. 2012, Article ID 258434, 48 pages, 2012.

[9] N. T. R. N. Kumara, P. Ekanayake, A. Lim et al., "Layered cosensitization for enhancement of conversion efficiency of natural dye sensitized solar cells," Journal of Alloys and Compounds, vol. 581, pp. 186-191, 2013.

[10] Q. Miao, M. Wu, W. Guo, and T. Ma, "Studies of highefficient and low-cost dye-sensitized solar cells," Frontiers of Optoelectronics in China, vol. 4, no. 1, pp. 103-107, 2011.

[11] J. Lee, R. W. Durst, and R. E. Wrolstad, "Determination of total monomeric anthocyanin pigment content of fruit juices, beverages, natural colorants, and wines by the $\mathrm{pH}$ differential method: collaborative study," Journal of AOAC International, vol. 88, no. 5, pp. 1269-1278, 2005.

[12] Q. Sun and L. Yang, "The adsorption of basic dyes from aqueous solution on modified peat-resin particle," Water Research, vol. 37, no. 7, pp. 1535-1544, 2003.

[13] N. T. R. N. Kumara, P. Ekanayake, A. Lim, M. Iskandar, and L. C. Ming, "Study of the enhancement of cell performance of dye sensitized solar cells sensitized with Nephelium lappaceum (F: Sapindacea)," Journal of Solar Energy Engineering, vol. 135, no. 3, 5 pages, 2013.

[14] N. T. R. Kumara, M. R. R. Kho, A. Lim et al., "DFT/TDDFT and experimental studies of natural pigments extracted from black tea waste for DSSC application," International Journal of Photoenergy, vol. 2013, Article ID 109843, 8 pages, 2013.

[15] K. Y. Foo and B. H. Hameed, "Insights into the modeling of adsorption isotherm systems," Chemical Engineering Journal, vol. 156, no. 1, pp. 2-10, 2010.

[16] N. M. Agyei, C. A. Strydom, and J. H. Potgieter, "An investigation of phosphate ion adsorption from aqueous solution by fly ash and slag," Cement and Concrete Research, vol. 30, no. 5, pp. 823-826, 2000.

[17] Y. S. Ho and G. Mckay, "Competitive sorption of copper and nickel ions from aqueous solution using peat," Adsorption, vol. 5, no. 4, pp. 409-417, 1999.

[18] S. Baup, C. Jaffre, D. Wolbert, and A. Laplanche, "Adsorption of pesticides onto granular activated carbon: determination of surface diffusivities using simple batch experiments," Adsorption, vol. 6, no. 3, pp. 219-228, 2000.

[19] A. Benhammou, A. Yaacoubi, L. Nibou, and B. Tanouti, "Adsorption of metal ions onto Moroccan stevensite: kinetic and isotherm studies," Journal of Colloid and Interface Science, vol. 282, no. 2, pp. 320-326, 2005.

[20] V. C. Srivastava, M. M. Swamy, I. D. Mall, B. Prasad, and I. M. Mishra, "Adsorptive removal of phenol by bagasse fly ash and activated carbon: equilibrium, kinetics and thermodynamics," Colloids and Surfaces A, vol. 272, no. 1-2, pp. 89-104, 2006.

[21] S. J. Allen, G. Mckay, and J. F. Porter, "Adsorption isotherm models for basic dye adsorption by peat in single and binary component systems," Journal of Colloid and Interface Science, vol. 280, no. 2, pp. 322-333, 2004.

[22] W.-T. Tsai, H.-C. Hsu, T.-Y. Su, K.-Y. Lin, and C.-M. Lin, "Adsorption characteristics of bisphenol-A in aqueous solutions onto hydrophobic zeolite," Journal of Colloid and Interface Science, vol. 299, no. 2, pp. 513-519, 2006.

[23] A. Artola, M. Martin, M. D. Balaguer, and M. Rigola, "Isotherm model analysis for the adsorption of Cd (II), Cu (II), Ni (II), and $\mathrm{Zn}$ (II) on anaerobically digested sludge," Journal of Colloid and Interface Science, vol. 232, no. 1, pp. 64-70, 2000.

[24] F.-C. Wu, B.-L. Liu, K.-T. Wu, and R.-L. Tseng, "A new linear form analysis of Redlich-Peterson isotherm equation for the adsorptions of dyes," Chemical Engineering Journal, vol. 162, no. 1, pp. 21-27, 2010.

[25] J.-P. Wang, H.-M. Feng, and H.-Q. Yu, "Analysis of adsorption characteristics of 2,4-dichlorophenol from aqueous solutions by activated carbon fiber," Journal of Hazardous Materials, vol. 144, no. 1-2, pp. 200-207, 2007.

[26] A. Tor and Y. Cengeloglu, "Removal of congo red from aqueous solution by adsorption onto acid activated red mud," Journal of Hazardous Materials, vol. 138, no. 2, pp. 409-415, 2006.

[27] S. Kundu and A. K. Gupta, "Adsorption characteristics of As(III) from aqueous solution on iron oxide coated cement (IOCC)," Journal of Hazardous Materials, vol. 142, no. 1-2, pp. 97-104, 2007.

[28] A. Özer and G. Dursun, "Removal of methylene blue from aqueous solution by dehydrated wheat bran carbon," Journal of Hazardous Materials, vol. 146, no. 1-2, pp. 262-269, 2007.

[29] M. Grätzel, "Solar energy conversion by dye-sensitized photovoltaic cells," Inorganic Chemistry, vol. 44, no. 20, pp. 6841-6851, 2005. 

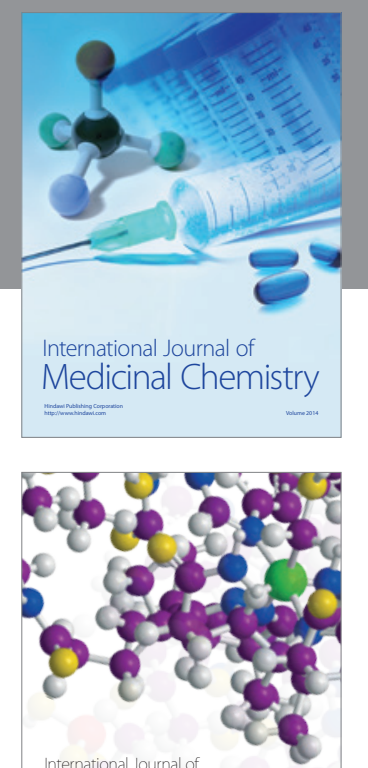

\section{Carbohydrate} Chemistry

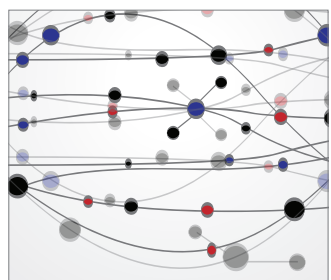

The Scientific World Journal
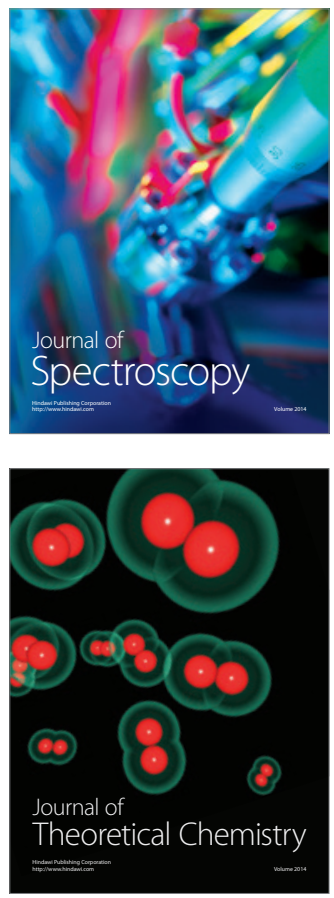
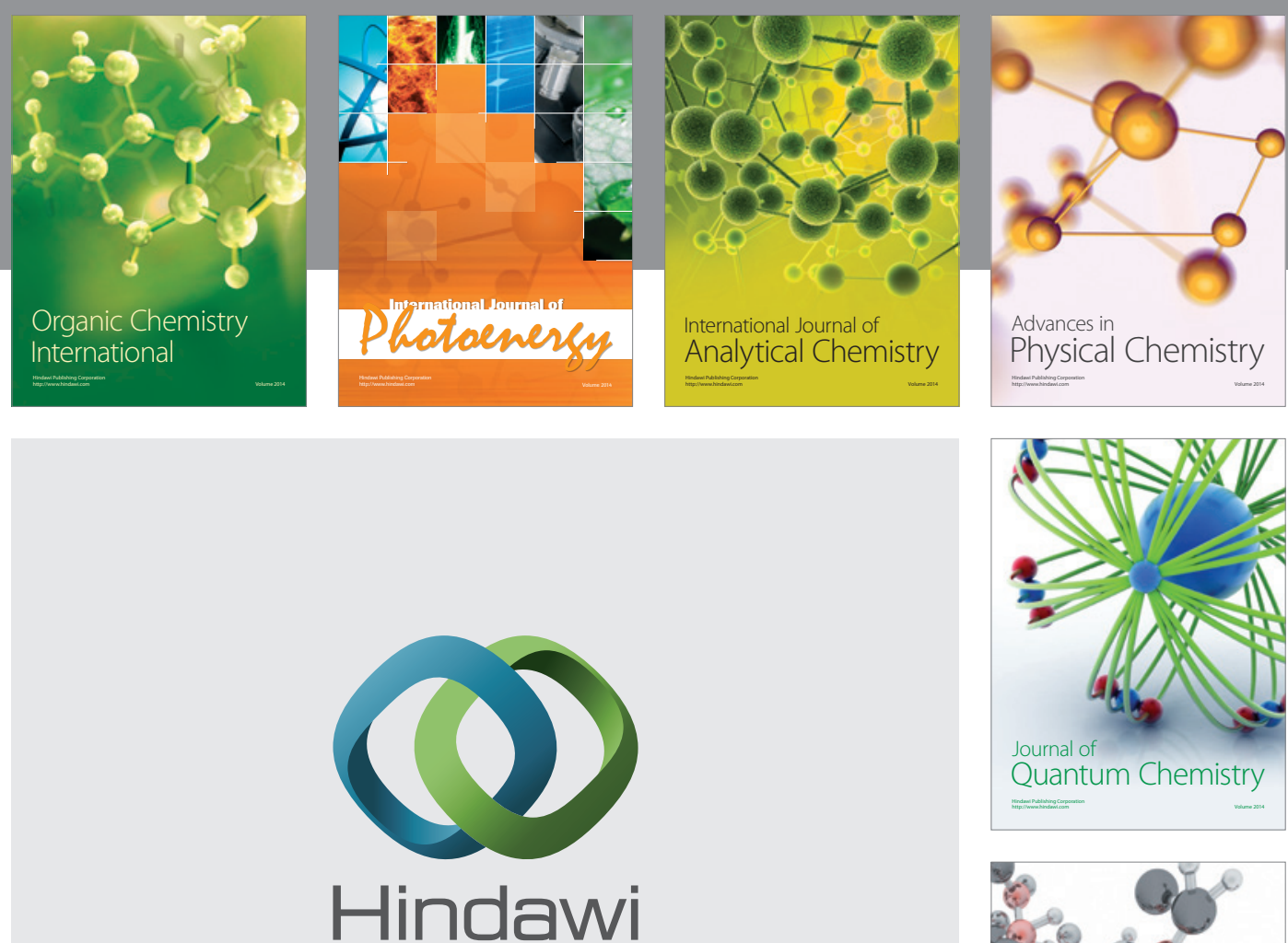

Submit your manuscripts at

http://www.hindawi.com

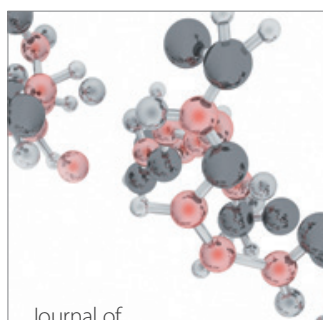

Analytical Methods

in Chemistry

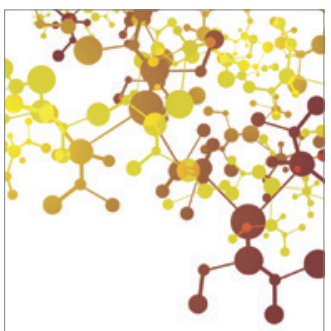

Journal of

Applied Chemistry

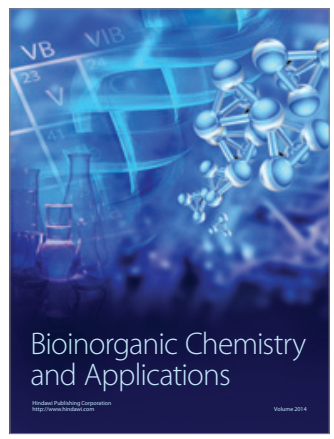

Inorganic Chemistry
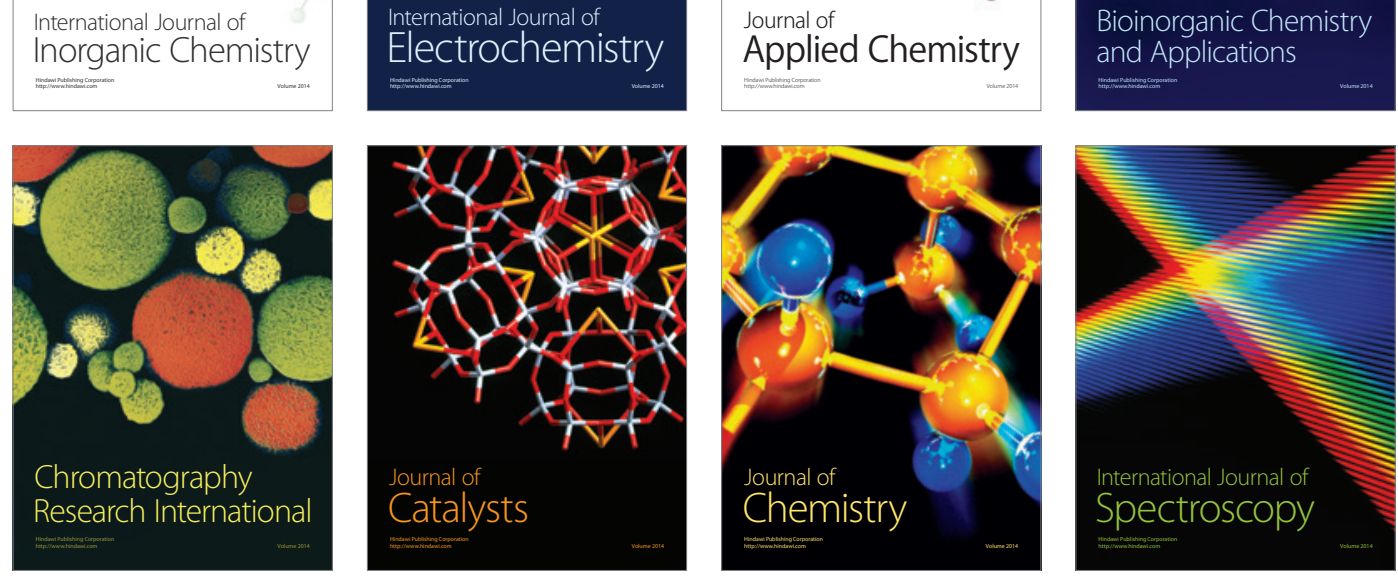